\title{
A SHEEP FAIR
}

THE day arrives of the autumn fair,

And torrents fall,

Though sheep in throngs are gathered there,

Ten thousand all,

Sodden, with hurdles round them reared:

And, lot by lot, the pens are cleared,

And the auctioneer wrings out his beard,

And wipes his book, bedrenched and smeared,

And rakes the rain from his face with the edge of his hand, As torrents fall.

The wool of the ewes is like a sponge

With the daylong rain:

Jammed tight, to turn, or lie, or lunge,

They strive in vain.

Their horns are soft as finger-nails,

Their shepherds reek against the rails,

The tied dogs soak with tucked-in tails,

The buyers' hat-brims fill like pails,

Which spill small cascades when they shift their stand

In the daylong rain.

POSTSCRIPT

Time has trailed lengthily since met

At Pummery Fair

Those panting thousands in their wet

And woolly wear:

And every flock long since has bled,

And all the dripping buyers have sped,

And the hoarse auctioneer is dead,

Who 'Going - going!' so often said,

As he consigned to doom each meek, mewed band

At Pummery Fair. 